\title{
A CULTURA MIDIÁTICA INFANTIL E A CONSTRUÇÃO DA NOÇÃO DE TEMPO HISTÓRICO
}

Alexia Pádua Franco*

RESUMO: O presente artigo pretende analisar como desenhos animados infantis e revistas infanto-juvenis abordam a noção do tempo quando tratam de temas históricos. A partir destas análises, tem-se a intenção de pensar como estes produtos midiáticos podem ser discutidos nas aulas de História das séries iniciais do ensino fundamental, favorecendo a reflexão e a formação da noção de tempo histórico.

Palavras chave: Tempo histórico. Mídia. Ensino de História.

CHILDREN's MEDIA CULTURE AND THE CONSTRUCTION OF THE NOTION OF HISTORICAL TIME

ABSTRACT: This paper examines how cartoons and magazines for children approach the notion of time when they deal with historical themes. These analyses are intended to think how these media products can be discussed in history classes of the first grades of elementary school to encourage reflection and the formation of the concept of historical time

Key words: Historical Time. Media. History Classes.

Doutora em Educação e professora da Escola de Educação Básica da Universidade Federal de Uberlândia (UFU). E-mail: alexiapadua@centershop.com.br 


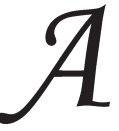

construção da noção de tempo histórico nas crianças é um fenômeno histórico-cultural que não se restringe apenas ao espaço escolar, mas também envolve vários outros espaços sociais (a mídia, através dos programas de tevê, das publicações impressas, das músicas, dos jogos eletrônicos, é um deles) que participam da formação dos sujeitos. Uma formação nem um pouco coerente, homogênea, mas perpassada por diferentes visões de mundo relacionadas a múltiplos projetos e práticas sociais. Neste sentido, vamos aqui refletir sobre como alguns produtos midiáticos voltados para o público infantil contribuem para o desenvolvimento da noção de tempo histórico e como a escola, através do ensino de História, pode e deve dialogar com as representações de tempo que aí circulam para favorecer uma formação histórica mais crítica.

\section{O tempo histórico na mídia}

Vivemos, principalmente nas democracias ocidentais, uma época de desenraizamento, em que a "tirania do novo", a desvalorização do passado, a exaltação ao imediato e efêmero geram um grande desinteresse pelas tradiçôes culturais, pelo processo histórico, e podem "comprometer o desenvolvimento da noção de temporalidade histórica" (Siman, 2003, p. 125). Hobsbawn (1995, p. 13) afirma que

(...) a destruição do passado - ou melhor, dos mecanismos sociais que vinculam nossa experiência pessoal à das gerações passadas - é um dos fenômenos mais característicos e lúgubres do final do século xx. Quase todos os jovens de hoje crescem numa espécie de presente contínuo, sem qualquer relação com o passado público da época em que vivem.

Paradoxalmente, vivemos também uma "febre da memória" (Huyssen, 2000, p. 35), causada justamente pelo processo de desenraizamento que nos amedronta e angustia. Huyssen argumenta que "o enfoque sobre a memória é energizado subliminarmente pelo desejo de nos ancorar em um mundo caracterizado por uma crescente instabilidade do tempo e pelo fraturamento do espaço vivido" (op. cit., p. 20). Segundo este autor, a mídia é uma das principais responsáveis por tornar a memória cada vez mais disponível para o grande público: 
(...) desde a década de 1970, pode-se observar, na Europa e nos Estados Unidos, (...) a literatura memorialística e confessional, o crescimentos dos romances autobiográficos e históricos pós-modernos (...), a difusão das práticas memorialísticas nas artes visuais, geralmente usando a fotografia como suporte, e o aumento do número de documentários na televisão, incluindo, nos Estados Unidos, um canal totalmente voltado para história: o History Channel. (p. 14)

No Brasil, isso se evidencia, principalmente, a partir da comemoração dos 500 anos do país, na intensa produção e circulação de revistas, filmes, telenovelas, minisséries com temáticas relacionadas a períodos de nossa história. Publicaram-se revistas com temas históricos para o grande público (História Viva, da Duetto Editorial; Revista de História da Biblioteca Nacional; Aventuras na História, da Editora Abril), histórias em quadrinhos com enredo baseado em fatos históricos tradicionais (os gibis da Turma da Mônica, da Editora Globo, têm títulos referentes ao Descobrimento do Brasil, Independência, Inconfidência Mineira), enciclopédias e coleções de história voltadas para público de diferentes idades (o Núcleo de Revistas da Folha de S. Paulo lançou a coleção Disney Explora: 500 anos de Brasil, com 20 fascículos que abordam desde as "Grandes Navegações" até "O Fim do Império"). Foram produzidas minisséries e novelas de televisão com abordagem histórica: a Rede Globo, que habitualmente produz novelas com cenário histórico (Escrava Isaura é um exemplo tradicional), intensificou esta linha na época da comemoração dos 500 anos com a novela Terra nostra, as minisséries Invenção do Brasil e $A$ muralha e continua produzindo, pelo menos uma vez ao ano, minisséries como $J K$ e Amazônia. Ampliou-se também a projeção cinematográfica de filmes animados, de produção estrangeira, com algum tratamento histórico, como Pocahontas, Eldorado e Hércules.

Bittencourt (1997, p. 14), ao discutir os atuais desafios do ensino de História no Brasil, afirma que esta "história oferecida para as novas gerações é a do espetáculo, pelos filmes, propagandas, novelas, desfiles carnavalescos (...)". Huyssen (2000, p. 21), ao considerar as produções midiáticas sobre o Holocausto, também destaca essa "mercadorização e espetacularização em filmes, museus, docudramas, sites na internet, livros de fotografia, histórias em quadrinhos, ficção (...) e música popular”. No entanto, ele analisa que, mesmo neste contexto atual, em que a memória e o passado são tratados como mercadorias, 
nem tudo é banalizado; defende que não é possível menosprezar estes produtos culturais, pois

(...) não há nenhum espaço puro fora da cultura da mercadoria, por mais que possamos desejar um tal espaço. Depende muito, portanto, das estratégias específicas de representação e de mercadorização e do contexto no qual elas são representadas (...). O problema não é resolvido pela simples oposição da memória séria à memória trivial (...).

Nesse sentido, acredito que nas produções midiáticas haja um olhar heterogêneo sobre a questão do tempo histórico e que estas, mesmo como espetáculo, participam da formação do nosso olhar histórico, devendo assim ser consideradas em nossas reflexões.

\section{Flintstones e Hércules: a mumificação do tempo histórico}

Ao analisarmos, na mídia audiovisual e impressa, produções voltadas para o público infantil, encontramos diferentes representaçóes sobre o tempo histórico. Há desde aquelas mais tradicionais, que se baseiam no tempo contínuo, vazio e homogêneo do progresso, até aquelas "mais complexas, capazes de historicizar as práticas culturais, sociais ou sexuais que herdamos, não necessariamente para extrair lições do passado, mas para nos libertarmos dele, ou ainda para relativizá-lo a partir do contato com modos de vida diferenciados" (Rago, 2003, p. 29).

Alguns filmes animados construídos em cenários históricos não se preocupam com a alteridade cultural no tempo, ou seja, com as diferenças e semelhanças entre as múltiplas organizaçóes sociais que existiram e coexistiram em diferentes tempos históricos, as permanências e rupturas do processo histórico. Dirigem-se ao passado apenas para explicar a origem do presente, procurando continuidades, evoluções, não percebendo as rupturas, as diferenças inconciliáveis entre um tempo e outro.

O desenho animado Flintstones, produzido pelos estúdios Hanna Barbera, constrói a ideia de passado como germe do presente, de continuidade histórica, fazendo uma apologia ao mundo capitalista, em vários aspectos: situa "homens da caverna" em cidades, com ruas, residências para cada família, enfim, anacronicamente, situa em um espaço urbanizado homens que viviam coletivamente no campo; preenche 
o cotidiano destes homens de objetos tecnológicos semelhantes aos de hoje, porém mais rústicos, movidos por força animal; mostra situações de trabalho assalariado, baseadas na relação capitalista patrão-empregado.

O filme animado Hércules, produzido pela Disney em 1997, também provoca esta confusão entre passado e presente, naturalizando as características da sociedade capitalista, em vários aspectos, e reforçando uma representação de tempo histórico que torna homens e mulheres do presente prisioneiros de um passado homogeneizado, dificultando-lhes a possibilidade de acreditar em transformações radicais em sua maneira de viver. A cidade da Grécia, onde se desenrola a história, tem trânsito organizado como o nosso, com faixas para pedestre; o vendedor de rua usa um relógio Rolex. Quando as musas cantam as vitórias de Hércules, o sucesso do herói é representado como o de hoje, em que tudo vira objeto de consumo: Hércules deixa sua marca na "calçada da fama”, dá autógrafos, são espalhados outdoors com sua imagem, produz-se e se consome em larga escala (como se houvesse produção fabril na Grécia antiga) sandálias, potes de cerâmica, bonecos, copos, refrigerantes com o logotipo $\mathrm{H}$. Alguns objetos vendidos são como aqueles produzidos na Antiguidade (sandálias de tiras, potes de cerâmica), outros são como os nossos (refrigerante, copo de plástico com canudo, bonecos em miniatura). Enfim, mistura-se a Antiguidade grega e o presente capitalista, compondo o "samba do crioulo doido". Além disso, constrói-se um cenário que cria a sensação de que o consumismo sempre existiu, incentivando as crianças a comprarem mais os produtos da Disney que são semelhantes aos consumidos, no filme, pelas crianças gregas. Como observa Giroux (1995, p. 60),

(...) conectando de forma bem sucedida os rituais de consumo com o hábito de ir ao cinema, os filmes animados da Disney fornecem um "mercado da cultura”, uma plataforma de lançamento para um infindável número de produtos e mercadorias que incluem fitas de vídeo, discos com trilhas sonoras, roupas infantis, móveis, brinquedos e novas atrações nos seus parques de diversão.

Flintstones (onde o passado é o "presente rústico") e Hércules (onde o passado é mais que o embrião do presente; é a sua cópia fiel) reforçam a noção de tempo histórico que, conforme Oliveira (2003, p. 164), é mais comum entre as crianças: "tudo o que elas conhecem 
sempre existiu no passado, só que de forma diferente". Como percebido por Piaget (1998), para grande parte dos meninos e meninas entre 7 e 10 anos, tudo o que há no presente já existia no passado, só que de forma mais rústica, embrionária. Em outras palavras, estes filmes animados reforçam um olhar histórico que mumifica a vida, fossiliza o tempo, podendo gerar um sentimento de desesperança, depreciando a possibilidade de criação e transformação, amputando o novo e a utopia.

Revista Recreio: do tempo linear às múltiplas temporalidades

A Revista Recreio, publicada semanalmente pela Editora Abril, aborda historicamente diferentes temas relacionados ao cotidiano das crianças ou à sua curiosidade, a personagens históricos, cientistas e artistas, e também a acontecimentos históricos que têm sido foco de novelas, filmes e desenhos infantis, ou são vinculados a eventos culturais ou datas comemorativas tradicionalmente veiculadas na mídia e na escola.

Estes artigos (Recreio, 1999-2005) ficam em uma seção voltada especificamente para a questão da História - Túnel do Tempo -, ou em outras seçōes (Pelo Mundo, Esportes, Escola, Fique Ligado, Ciência), onde se enfoca de maneira transdisciplinar um determinado assunto. A maioria deles tem um viés temático, ou seja, apresenta um mesmo tema em diferentes espaços e épocas históricos.

Poucos representam o passado da forma tradicional ao construir uma narrativa histórica baseada numa sequência cronológica linear, que se inicia no passado mais remoto e, a partir dele, inventa os acontecimentos que conduziram ao momento que se quer explicar e, até mesmo, legitimar. Para não romper essa sequência, detêm-se no passado, não relacionando os momentos históricos estudados com problemas da atualidade. Este é o caso das biografias que falam da história individual de personalidades e de seus feitos, sem nem relacioná-los com o contexto da época. É o caso também de artigos que tratam de tempos mais distantes ou fatos históricos tradicionais, como o artigo Sonho de liberdade: saiba por que Tiradentes foi tão importante para o Brasil, que se restringe a uma competente síntese das causas da Inconfidência Mineira, da origem e destino de seus participantes mais ilustres, de outros movimentos que lutaram pela Independência do Brasil durante os séculos XVIII e XIX e suas consequências. 
No entanto, nem sempre os tradicionais fatos da história e datas comemorativas são enfocados desta forma. $\mathrm{Na}$ maioria das vezes, além de sintetizar o processo que desencadeou o acontecimento em questão, faz-se uma leitura crítica dele e das suas fontes históricas: o artigo Dia de Festa analisa o quadro de Pedro Américo sobre a Independência do Brasil, destacando diferentes partes deste para mostrar como "a cena ficou diferente do que realmente aconteceu, para que a pintura ficasse mais bonita e mostrasse dom Pedro como herói”. Relaciona-se passado e presente de grupos sociais que viveram experiências semelhantes, discute-se mudanças e permanências, diferentes sujeitos históricos envolvidos, propõe-se reflexões sobre questões da atualidade relacionadas ao fato estudado. Um exemplo é o artigo $O$ fim da escravidão, que trata da vinda dos africanos para o Brasil colonial, de suas difíceis condiçôes de trabalho, das várias leis criadas na tentativa de diminuir o uso do trabalho escravo e seus limites, da assinatura da Lei Áurea não como "uma decisão pessoal da princesa", mas resultado de movimentos organizados, de rebeliōes escravas e pressão internacional. Discute a ineficácia desta lei para melhorar as condições de vida dos negros libertos, as lutas existentes até hoje pela "igualdade de direitos e oportunidades para brancos e negros", além de propor pesquisas e discussóes em grupo sobre questôes como: "será que pessoas de raças, religiôes e origens diferentes ainda enfrentam preconceito em muitos lugares do mundo?".

Entre os artigos com viés temático, há aqueles que, ao abordarem a história dos meios de comunicação (Alô, Alô! Tem alguém aí), do dinheiro ( $O$ dinheiro tem cada história!), do relógio (Que horas são?) e outras invençóes, tratam da alteridade cultural no tempo com preconceitos e de forma etnocêntrica. Olham o ontem a partir do hoje e, por isso, consideram-no "inferior", como um tempo ainda não beneficiado pelo progresso do presente e, por não ter a tecnologia e os costumes de hoje, repleto de dificuldades. São artigos construídos com expressōes como "dava um trabalhão", "nem sempre foi tão fácil", "antigamente, as pessoas tinham que usar a imaginação", "foram milhares de anos de confusão".

Há também artigos que, ao olhar o ontem a partir do hoje, apesar de não hierarquizar os grupos que viveram em diferentes épocas, são anacrônicos, pois procuram entender os hábitos de uma comunidade com referências de outra, de outro tempo. Em Beleza colorida, 
olha-se para o passado para mostrar como, desde longínquos tempos, em diferentes organizações sociais, as pessoas já usavam maquiagem "para ficarem bonitas". Nesta busca da continuidade, chega-se ao paradoxo de denominar de "um dos primeiros produtos de beleza", uma pasta avermelhada passada nos lábios pelos homens das cavernas para deixar "os guerreiros com cara de bravos" e "assustar os inimigos".

A grande maioria dos artigos da revista Recreio que traz alguma abordagem histórica o faz relacionando passado e presente de uma forma menos linear, etnocêntrica e anacrônica do que as analisadas até aqui. Eles mostram, mesmo que de forma bem sintética, em artigos pequenos voltados para atrair a leitura infantil, diferenças e semelhanças, mudanças e permanências entre várias épocas e lugares históricos.

Algumas vezes, relaciona-se passado-presente para mostrar como hábitos, costumes e objetos que existem atualmente já existiam no passado. $\mathrm{Na}$ construção deste conhecimento, encontramos duas abordagens concomitantes ou não. Uma que, em artigos iniciados com as expressões "descubra como surgiram...", "saiba como foram inventados...", "descubra como nasceu...", busca o germe do que há hoje, destacando as descobertas e necessidades humanas que levaram a algumas mudanças nestes costumes e a evolução tecnológica dos objetos. Outra que, além disso, observa como grupos sociais de outros espaços e tempos atribuíam significados e usos diferentes ao que temos na atualidade. Nestes artigos, as diferenças, ao invés de serem classificadas como melhores ou piores, são entendidas como relacionadas a diferentes interesses e condições de vida. Assim, nos artigos sobre crianças em diferentes tempos e lugares (Viagem no tempo) e sobre a história dos talheres (Como se come?), há, respectivamente, comentários como

(...) Que tal viajar ao passado e conhecer crianças de diferentes épocas e lugares do mundo. Só não adianta levar o seu videogame na mala: ninguém vai saber jogar. Mas não tem problema, você vai descobrir novos jeitos de brincar (...).

(...) antigamente, não existiam pratos e talheres e quase todo mundo comia com as mãos, colocando os alimentos sobre o pão. Mesmo depois da invenção dos talheres, pouca gente os utilizava, porque se acreditava que interferiam no sabor da comida (...). Na Europa, as pessoas ricas se serviam com garfos, colheres e facas de ouro, prata e bronze e as pobres só tinham utensílios feitos de madeira e osso (...). 
Há também passagens em que as diferenças são ressaltadas como aspectos curiosos e exóticos de povos que não vivem como nós, o que pode construir a ideia de que a normalidade está no hoje; o ontem é "maluquice", reforçando preconceitos, pensamentos etnocêntricos. Por exemplo, o artigo Escolas bem malucas tem frases como "já pensou ter de aprender 700 letras (Egito antigo)...?", "Há muitos anos se usava nos Estados Unidos uma cartilha engraçada: as letras eram paezinhos e, depois de aprender uma delas, o aluno podia comê-la como prêmio!" (grifo nosso).

Em outros artigos que relacionam passado e presente, é ressaltado como nos apropriamos de fatos, hábitos do passado, dando a eles usos culturais diferentes ao criar expressōes de linguagem, e até acarretando a permanência, ao menos simbólica, de costumes que nem existem mais. Por exemplo, o artigo Caiu a ficha? mostra a relação de expressôes muito usadas por nós - como "caiu a ficha", "disque-pizza", "colocar o carro na frente dos bois", "andar na linha", "pegar o bonde andando" - com meios de transporte e comunicação que já quase desapareceram: telefones públicos que funcionavam com o uso de fichas e não de cartôes magnéticos, telefones de disco no meio e não de teclas, carro de boi, trem, bonde.

Há também aqueles artigos que representam não só as semelhanças entre as várias organizaçōes sociais existentes ao longo do tempo, mas principalmente suas singularidades. Enfocam modos de vida do passado, preocupando-se em destacar como as pessoas viviam de forma diferente - nem melhor, nem pior - do que hoje estamos acostumados. $\mathrm{O}$ artigo Trabalhos diferentes aborda profissōes que não existem mais, mas eram importantes para outros povos. Em Ai vem um novo século são destacados diferentes calendários. Enfim, são artigos que se aproximam timidamente do desafio proposto por Rago (2003, p. 29):

(...) a historicização das formas predominantes de organização da vida social no presente permite desnaturalizá-las e relativizá-las, o que é condição sine qua non para invenção de novos modos de vida (...). A História pode mostrar racionalidades e experiências muito distintas das contemporâneas, não necessariamente para nortear nossa existência na atualidade, mas para inspirar-nos a pensar diferentemente, (...) estabelecendo outros nexos e conexões (...). 
Assim, essas passagens da revista Recreio podem incentivar o leitor a pensar sobre a heterogeneidade, a historicidade do que parece natural, uno, absoluto; criar a perspectiva de que não há um caminho certo e único para o futuro, podendo estimular os indivíduos a abandonarem o comodismo e o ceticismo e a (re)pensarem diferentes alternativas de transformação social.

Outros artigos, como Viagem à Idade da Pedra, ao contrário dos já discutidos, além de expor como os homens do passado viviam de forma diferente de nós, ressalta as contribuiçôes que eles deram à humanidade - como o controle do fogo, a invenção de ferramentas, a domesticação de animais, a agricultura -, concluindo que, "com essas descobertas todas, a vida de todos foi mudando (...). Depois disso, não pararam mais de ter ideias novas e de desenvolver invençōes para melhorar a vida de todo mundo". Enfim, representa o passado sem desqualificá-lo, destacando como os homens sempre buscaram alternativas para vencer os desafios que enfrentavam. Assim, pode contribuir para amenizar o pessimismo marcante de nossos tempos e desenvolver a crença de que somos capazes de criar um mundo melhor.

Observamos, então, que, em uma mesma revista infanto-juvenil, há uma diversidade de olhares sobre a alteridade cultural no tempo, o que também, com certeza, acontece entre os desenhos e filmes animados. Aqui analisamos Flintstones e Hércules, que têm um olhar semelhante, mas se pode pesquisar outros, encontrando outras perspectivas.

Vamos agora pensar como o ensino de História pode aproveitar a contribuição destes vários olhares midiáticos sobre o tempo histórico.

\section{O ensino de História e os olhares midiáticos sobre o tempo histórico}

Quando defendemos que a educação histórica desenvolvida na escola precisa levar em conta as experiências das crianças, não devemos nos limitar àquelas vividas junto aos grupos sociais como família, escola, bairro, mas também considerar aquelas vividas no consumo dos produtos midiáticos.

Tais produtos precisam ser levados para a sala de aula não apenas para torná-la "mais interessante" ou para ilustrar uma informação, mas para discutir suas representações e confrontá-las com outras. 
O objetivo disso não é negá-las ou desqualificá-las como menos verdadeiras ou sérias, mas ajudar os alunos a perceberem que vivem em um jogo de representações que precisam ser entendidas criticamente para que eles possam construir um pensamento autônomo.

Para isso, é importante considerar e discutir os diferentes sentidos que os alunos constroem ao verem um determinado filme ou lerem um artigo de revista, considerando que os produtos midiáticos não formam noções de tempo histórico nas crianças de maneira totalizante. Leitores e telespectadores reelaboram de diferentes maneiras estes tempos, conforme sua bagagem cultural, os outros espaços de formação de que participam, seus interesses (Martín-Barbero, 1995).

Entre os produtos midiáticos aqui analisados, alguns (Hércules, Flintstones, certos artigos da revista Recreio) podem reforçar a visão etnocêntrica do aluno, fazendo-o olhar para outros tempos e espaços com base nos seus valores e parâmetros de julgamento, o que dificulta a percepção da possibilidade de transformar, de ser diferente. No entanto, há aqueles que podem contribuir para um movimento de descentração, ao tratar das mudanças e permanências, diferenças e semelhanças entre vários lugares e épocas históricas. Em sala de aula, as professoras podem confrontar estes diferentes olhares midiáticos sobre o passado, desconstruindo-os junto aos alunos para perceber que existem várias maneiras de se entender o passado e que, cada um delas, favorece formas diferentes de agir no presente e pensar o futuro - conformistas ou não. Ao trabalhar estes artigos, que são, na sua maioria, temáticos, é preciso ter cuidado para não fragmentar a história, ou seja, para não considerar o tema em questão de forma descontextualizada, como mera curiosidade. Para isso, é importante cruzar várias fontes, no sentido de contextualizar o tema discutido, mostrando sua relação com outros aspectos da vida humana nos tempos e lugares históricos estudados.

Esta proposta caminha na contramão do que Tuma (2003) percebeu em uma pesquisa realizada junto a professores das séries iniciais do ensino fundamental, as quais norteiam sua prática docente conforme

(...) um arquétipo do tempo repetitivo, organizado, disciplinado e controlado que se mescla ao tempo cíclico na busca da homogeneização temporal, para anulação da diferença e da desordem (...) um tempo racional, homogêneo, mecânico, evolutivo, uniforme, métrico, produtivo, linear e cumulativo. (p. 236) 
Assim, para professores e professoras contribuírem no processo de apropriação crítica das noções de tempo histórico presentes nos produtos midiáticos, é preciso que eles próprios desconstruam esta sua noção de tempo predominante na atualidade urbano-industrial e, inclusive, nas escolas. É preciso entender, como Miranda (2003, p. 201), que "para o aluno, sair do presente significa se descentrar, deixar de tomar seus valores e parâmetros de julgamento, para analisar outras realidades e outras culturas. A História é (...) a disciplina que potencializa, como poucas outras, tal movimento de descentração".

Vale enfrentar este desafio, pois este é o papel da escola e, em particular, do ensino de História: não ensinar verdades prontas, mas levar os alunos a refletirem sobre os múltiplos e contraditórios olhares que fazem parte de sua vivência e de sua formação, para que possam, autonomamente, apropriar-se com criticidade destes e pensar na sua atuação social e política.

Recebido em junho de 2009 e aprovado em novembro de 2009.

\section{Referências}

BITTENCOURT, C. Capitalismo e cidadania nas atuais propostas curriculares de História. In: BitTencourt, C. (Org.). O saber histórico na sala de aula. São Paulo: Contexto, 1997. p. 11-27.

GIROUX, H.A. A disneyzação da cultura infantil. In: Silva, T.T.; Moreira, A.F.B. (Org.). Territórios contestados: o currículo e os novos mapas culturais e políticos. Rio de Janeiro: Vozes, 1995. p. 49-81.

HOBSBAWN, E. A era dos extremos: o breve século xx (1914-1991). São Paulo: Companhia das Letras, 1995.

HUYSSEN, A. Seduzidos pela memória: arquitetura, monumentos, mídia. Rio de Janeiro: Aeroplano, 2000.

MARTÍN-BARBERO, J. A América Latina e os anos recentes: o estudo da recepção em comunicação social. In: SousA, M.W. (Org.). Sujeito: o lado oculto do receptor. São Paulo: Brasiliense; ECA-USP, 1995. p. 39-68. 
MIRANDA, S.R. Reflexões sobre a compreensão (e incompreensões) do tempo na escola. In: De Rossi, V.L.S.; Zamboni, E. (Org.). Quanto tempo o tempo tem!. Campinas: Alínea, 2003. p. 173-188.

OLIVEIRA, S.R.F. O tempo, a criança e o ensino de História. In: DE Rossi, V.L.S.; Zamboni, E. (Org.). Quanto tempo o tempo tem!. Campinas: Alínea, 2003. p. 145-172.

PIAGET, J. Psicologia da criança e o ensino de História. In: PArrat, S.; Tryphon, A. (Org.). Sobre a pedagogia. São Paulo: Casa do Psicólogo, 1998. p. 89-95.

RAGO, M. O historiador e o tempo. In: De Rossi, V.L.S.; Zamboni, E. (Org.). Quanto tempo o tempo tem!. Campinas: Alínea, 2003. p. $25-48$.

RECREIO. São Paulo: Abril, 1999-2005. (CD-ROM).

SIMAN, L.M.C. A temporalidade histórica como categoria central do pensamento histórico: desafios para o ensino e aprendizagem. In: DE Rossi, V.L.S.; Zamboni, E. (Org.). Quanto tempo o tempo tem!. Campinas: Alínea, 2003. p. 109-144.

TUMA, M.M. Tempo disciplinar escolar: representações de professoras. In: De Rossi, V.L.S.; Zamboni, E. (Org.). Quanto tempo o tempo tem!. Campinas: Alínea, 2003. p. 205-239. 